\title{
THE INHERITANCE OF MUSICAL TALENT
}

\author{
By C. E. SEASHORE
}

$\mathbf{M}$

USICAL talent probably lends itself better than any other talent to the investigation of the laws of mental inheritance, for the reason that it does not represent merely a general heightening of the mental powers but is specifically recognized as a gift which can be analyzed into its constituent elements, many of which may be isolated and measured with reasonable precision. The inheritance of musical talent may, therefore, be studied, not only for itself, but also for the bearing that it has on the inheritance of mental traits in general.

Yet, in approaching this problem, we are forced to face certain complexities which tend to make the work difficult, and may at first seem insurmountable. Frank recognition of these is, however, the first step in scientific procedure. The more of such facts we discover early and take into account the more permanent will be the value of our labors. In the present paper I shall try to point out some of these elements in the situation and make a general forecast as to procedure.

\section{Mugical Talent Not One but a Group of Hierarchies of Talent}

The musical person may be distinguished in voice, in instrumental performance, in musical appreciation, or in composition; each of these are independent fields in which one may gain eminence without giving evidence of marked ability in the others. Then, within each of these four large avenues of musical life, we find numerous independent variables. Voice, for example, is a physical capacity which may be distinguished in volume, range, and timbre, all three quite independent variables and not necessarily associated with the musical mind.

On the sensory side we have a three-fold division of content as heard: namely, tone, time, and intensity, each forming a hierarchy of its own and quite independent of other talents. Each hierarchy of capacities runs as an independent branch, not only in sensation, but through memory, imagination, thought, feeling, 
and action. Each branch of this family tree throws out similar clusters of capacities. For example, the power of imagery, creative imagination, emotional warmith, and logical grasp, tend to appear in all three of these branches, except to the extent that they are excluded by the limitations of fundamental capacities for hearing one or more of these attributes.

In the investigation of inheritance we must, therefore, abandon the plan of merely counting persons musical or unmusical, and patiently settle down to the isolation and observation of isolable traits; such as, the inheritance of the sense of pitch, creative imagination, motor imagery, a large register of the vocal chords, excellence in motor control, or musical intellect.

\section{Capacity versus Achievement}

The investigator of inheritance is not interested primarily in the degree of achievement attained, which is usually a circumstance of fortune or misfortune in environment; he has to do exclusively with the valuation of inborn capacities. The term capacity is used in psychology to denote inborn power, whereas the term ability is used to denote acquired skill in the use of a given capacity. Skill, or achievement is significant only in so far as it gives evidence of native capacities. It is manifestly unjust to attempt to trace musical inheritance in terms of distinguished achievement in music. Wherever we find achievement we count it as evidence of capacity; but we must employ ways and means of rating undeveloped capacities fairly in comparison with capacities which have been given natural outlets for development into achievement.

This point of view is fundamental and must be taken seriously. So long as we rate the presence of musical talent in terms of musical achievement we shall be dealing mainly with the superficial sociological and pedagogical phenomena of opportunities and scope of musical training, or the effect of inhibiting circumstance on the spontaneous self-expression in music.

Investigation of inheritance has been made possible for the first time by the introduction of methods of psychological examination in which we can discover, measure, and rate the existence, kind, and extent of natural musical capacities, quite independent of age, (beyond infancy) training, or musical performance. Most of us die "with all the music in us," but modern methods enable us now to observe and record the extent to which this is true, quite apart from its evidence in a musical life. 


\section{The Normal Mind versus The Genius and The Defective}

The normal mind is musical and the normal body is the instrument for adequate expression of music. As we have seen, whether or not the person with a normal mind and body shall distinguish himself in music is largely a matter of circumstances in the way of opportunities for development and absence of suppressing forces.

Investigation of heredity will naturally center first on what is thought to be most tangible types of cases; that is, on the one hand the genius and on the other the defective. But this distinction is not as simple as it might seem at first to be, for musical genius may be of very many kinds, many of which are due to unrelated causes. Thus, we may have the genius in composing, in performing, or in interpreting music; one quite independent of the other, and in each genus of these a variety of species. Likewise, musical deprivation may be due to faulty hearing, inadequate association, inferior intelligence, and within each genus of these and similar categories may be various species, many of them entirely unrelated. We shall, therefore, not find much comfort in thinking of the genius or the defective as representing peculiarly tangible cases for we shall be compelled to deal with specific factors in analyzed concepts.

The normal mind is the average mind. But such average does not represent a single dead level for all the various human capacities. Thus, the two cases, $A$ and B, here represented in talent charts on the basis of the measurement of talents listed, may be regarded as typical of "average" musical minds, yet they are radically different as may be seen in a comparison of the charted capacities in the four profiles. It is not illuminating to call them "normal."

What is here illustrated in musical capacity is equally true for other capacities in human endowments. This is only saying in other words, "We normal people are so different." If, for example, we rank capacities on the scale from one to one hundred per cent., we may find the so-called "normal" endowed with a superbly high faculty in one capacity, and in another, equally important, markedly defective; in one he may rank $99 \%$, and in the other $2 \%$. There is nothing gained by speaking of this as representing the average; each one must be considered by itself.

Similarly, cases B and C, each examples of superior endowment in music, are radically different; both capable of great 
excellence in musical achievement, but of different kinds, and for different reasons. Each will tend to manifest brilliancy through those talents in which he is most highly endowed.

In other cases, which may be said to be relatively unmusical, each has one or more capacities through which proficiency in music may be realized provided the more favored capacities are hit upon in the narrow available form of musical achievement.

We shall, therefore, be compelled to narrow our concept of normal and defective to the designation of these in terms of specific and isolable talents upon which musical achievement must depend. When this is done the popular distinction of genius, normal, and defective loses its significance, just as the term "insanity" has come to be merely a legal term, while the physician deals with specific causes and symptoms of mental diseases and finds all sorts of interweavings between sanity and insanity.

\section{Genius AND ImpULse}

But we should distinguish between the talented person and the genius. The most distinctive trait of the musical genius is the fact that he finds in music a dominant interest, is driven to it by an impulse, burns to express himself in music. He is driven by an instinctive impulse or craving for music which results in supreme devotion to its realization. The talented person, on the other hand, gives evidence of unusual powers which may or may not be motivated by an instinctive impulse. The talented person tends to manifest specific skills while genius generalizes, creates, thinks in a large whole. To view genius merely as a talent is to view the waterfall in terms of measures of water or height instead of regarding it as water in action, falling, working, entrancing. The imposing manifestation of eternal grandeur in the graceful folds of the giant veil of water is a reality. But there would be no fall were there no gorge, quantity of water, or height of shelf. The functioning power is implied in the structural composition. So, in music, the impulse to live the life of music owes its existence to the high possession of other musical talents. In laying the foundations for a scientific study of heredity we may, therefore, content ourselves with describing the waterfall in terms of the shape of the gorge, the quantity of water, and the height of the fall; that is, in terms of capacity for sensing, executing, imaging, feeling music.

In literature and art, it is a well-known fact that we often find people desperately devoted to their art, that is, drawn by a 
dominant impulse to a given art object, who never achieve and who are finally spotted as hopeless. The impulse itself does not make the genius and may be a misleading guide.

\section{Verbatility and Plasticity of the Human Organism}

In stressing the classification in terms of inborn capacities as distinguished from developed skill or achievement, we must not neglect the equally important fact that the limits of achievement depend on the relationship of one capacity to another, and that inferior and medium capacities in some factor may constitute adequate support for excellence in some dominant capacity, and some capacity may be utterly lost without interfering prohibitively with the function of another. For example, one may be stone deaf and yet be a superior composer if he has had normal hearing at some period of his life; but though he be a genius of musical intelligence and lack creative imagination he can not create music.

The resourcefulness of the human organism is marvelous. Recently a one armed man won the national honors in marksmanship in various forms of shooting with gun and rifle. A one legged man became a rope dancer. The war cripples are astonishing us in so many directions by their performances after loss of parts of the body. The same is also true mentally, as the mind is more complicated and plastic than the body. It, therefore, requires great insight to distinguish real achievement reached after the overcoming of handicaps from the possession of talent. Such achievement, under handicap, is favored in music by the fact that the material of music is manifold and the avenues of expression are many. A person without a voice may play; a person with a small register of voice may have beautiful quality; a person lacking sense of tone may excel in the rhythmic aspects of music; a person lacking the sense of time may dwell in the tonal aspects; a person lacking emotion may excel in the more abstract processes of composition and musical criticism.

Now, in all such cases it will be necessary to deal with specific gifts, either unusual excellences or marked absence of excellences, and in all cases to rate natural capacities as distinguished from the acquired skill or ability.

This point of view throws a flood of light on the analysis of likes and dislikes, character of performance, and character of creation in music. Thus, a distinguished singer was found to be inferior in the sense of pitch, and in this was found the explanation 
of the fact that she had failed in several rôles of music before she hit by chance upon the rôle of folk-songs in which she appears in solo and in which she, without apparent extravagance, makes use of the artistic liberties which the folk-singers take with their melodies. She has a beautiful voice, wide compass, and very effective support, from a dramatic point of view, in a graceful body and a beautiful face, so that appeal to the eye dominates the æsthetic appeal of the tonal message.

Persons who lack a sense of time or a sense of intensity are common in musical circles. The relative absence of feeling, imagination, or intellect in persons who have attained distinction in music is a notorious phenomenon. Many persons prominent in musical circles perform in a certain mechanical way and are always pronounced unmusical by the connoisseur; the voice lacks life, the rhythm is mechanical, the tone is cold. In any investigation of heredity we may have to call these highly trained persons unmusical on the basis of rating in natural capacities.

\section{Atritude of the Artist}

We can apply mental tests to rate the capacities of soldiers under military command, and the youth must accept the consequence of the rating whether it be favorable or unfavorable to his military career. In the schools there has now been established a variety of systems of tests by which the "gifts of nature" in the pupil are thrown into relief for the guidance of the educator, and children are coming to look upon the intelligence quotient, mathematical rating, and the learning curve as matters of routine, which they regard with the same complacence as they view their measures of height, weight, and lung capacity. The prospective musician in the music school is eager to secure her talent chart as a basis for the organization of her course, the identification and analysis of encountered difficulties, and the forecast of prospects in a musical career.

But when we attempt to follow up the individuals in a family of musicians with all its collateral branches we encounter prejudices, fears, scruples, and other negativisms, born of ignoranceignorance quite excusable in this ultra-modern movement of applied science. Apart from this there is in the very warp and woof of the musical temperament an attitude of mind, which by its very æsthetic glow is opposed to cold scientific procedure with particulars. This aloofness of the artist is also partly justified by the fact that the necessary procedure for the scientific 
investigation of musical inheritance is yet crude and has not yet become a part of the common stock of well recognized custom.

\section{Absence of Estabuished Biological Theory}

This reserve is further supported by the barren situation as regards established biological concepts of the physical mechanism in the inheritance of mental traits by transmission through the germ plasm. There must, for some time to come, be a patient procedure by "trial and error" in an attempt to try out the best working hypotheses now available. We have but little precedent for the application of Mendelian principles to mental traits. But from the point of view of modern psychology the prospect of drawing analogies from related experiments in plants and animals is very hopeful. Indeed, that is the only logical and economic way to proceed. We may accept, as a general working basis, the Mendelian hypothesis, and proceed to ascertain what determiners in the germ plasm function for musical talent; which are dominant and which are recessive; which musical dispositions are carried on the same determiner, and which are carried on determiners charged with non-musical factors, etc. In psychology, this will be virgin soil.

\section{Apparently Only of Theoretical Significance}

It would be difficult at the present stage to convince the patrons of applied psychology that this problem has any practical bearing, and this would be particularly the case with the musician who regards everything artistic as something almost beyond nature, at least very ethereal and sacred. Yet if it should prove possible to identify heritable musical traits, as we believe it is, and the laws of the operation of this inheritance should become common knowledge, it is conceivable that the gain for the development of artistic resources would be as enormously far-reaching in consequence for musical art as knowledge of such laws is proving to be in conservation of favorable and the elimination of unfavorable traits in animals and plants. And this may all come about without any eugenic infringement of the rights and finer sensibilities of esthetic man in human evolution.

\section{The Discarding of the Literature on Musical Inheritance}

The above facts, and many others like them, prove conclusively, to those acquainted with the literature of the subject 
that we can get little or no help from works now extant on the inheritance of musical talent. The mass of musical biography and autobiography has sprung up in terms of loose and utterly unscientific concepts. True, when we adopt a scientific terminology, it may be possible to go back and identify specific factors in compositions, published musical criticism, and a variety of other objective evidence of the presence of similar traits in successive generations of certain musical families. But it will be difficult to determine how much to attribute to nature and nurture respectively. Even then it will be like counting only the ships that come in for we can get but scant information about the musical nature on the maternal side. The male musical genius has often come from a mother whose extraordinary talent has passed undiscovered until it has appeared in the career of a son. To trace inheritance we must count all the members of a family of blood relations including certain collaterals, and attach as much significance to the rating of talent which has found no outlet for expression as to that which has found expression. This has not been done in musical biography because biography deals primarily with achievement.

In the few biometric studies of inheritance traits in which musical inheritance has been taken into account, the data obtained and the technique developed are of little value because none of them deal with specific capacities.

To those who are not trained in the technique of individual psychology of biometric experiments this discarding of the contributions of the past may seem sweeping and even arrogant; yet such is the process of clearing away the rubbish before breaking ground for a scientific venture in this field.

\section{The Experimental Merhod Essential}

Where there is no experiment there can be no science. Scientific investigation of musical talent had to wait for the appearance of the scientific psychology of music. Only in comparatively recent years have we seen the beginning of such a science. This science is still restricted to laboratories and other technical activities and has not yet invaded musical thought to any considerable extent. It is still in the inceptive stage, and the investigator of heredity must, therefore, content himself with a few aspects of musical talent which have been reduced to experimental control. In view of the considerations above mentioned we must now deal tentatively with such aspects as can be isolated, measured, and described with precision. To the investigator it is no sacrifice 
to abandon the hope of tracing the inheritance of musical talent as a whole. He prizes the opportunity of dealing with one specific capacity at a time.

\section{Measurement of Factors in Talent}

The whole subject of the analysis and measurement of musical talent is treated as fully as the material available at the present time permits in my recent volume "The Psychology of Musical Talent," (The Silver Burdette Co., Boston, 1919). The methods, means, and significance of the measures, ratings, and records here recommended are described in that volume.

Among the measures on specific factors of musical talent now available for use in quantitative procedure, $I$ would mention the following:

(a) The basic sensory capacities.-Beyond question the first thing to do is to measure quantitatively the three basic capacities; namely, the sense of pitch, the sense of intensity, and the sense of time. For these we have a standard of procedure, instruments, and norms readily available. Each of these represents a primary branch in the three-fold fork of the trees of musical talent; each should be followed further into its branching. The measurement of these three factors will reveal the actual psycho-physical capacities for the hearing of music because all musical sounds are perceived in these three forms. ${ }^{1}$

The sense of rhythm, the sense of timbre, and the sense of consonance are all complexes built up in various groupings of these three basic factors.

(b) The basic motor capacities.-In considering natural endowment for musical performance we must at once separate the two large divisions, singing and playing, and the latter must be considered in its various forms. Ultimately it will be necessary to employ distinct measures of aptness in singing and in playing of different instruments, but from the large eumber available, three may be selected for the present purpose. We may measure the capacity for control of pitch in terms of accuracy in the reproduction of pitch of a standard tone with the voice. For control of intensity we may measure natural precision in "touch" as shown in producing a tone of the standard loudness by pressing a key, guiding the loudness by ear. For control of time we measure

There is a fourth attribute of sound-extensity-which I am leaving out of account here; (1) because it depends upon the functioning of the pitch differentiating mechanism which we test in the sense of pitch; and $(\mathcal{Q})$ because it plays only a secondary role as one element of volume in music. 
accuracy in keeping time with a set standard. For each of these we have standardized instruments and methods of procedure.

These three measures of motor capacities parallel the measures of musical hearing. It is evident that each of these three capacities for action rests upon its corresponding capacity for hearing.

(c) Musical imagery.-While we relive and create music through images in all the senses, two are characteristic of musical life and essential; namely, auditory imagery, and motor imagery. We must determine auditory imagery because it is in terms of this that we relive music in the nature of sounds which we have once heard and express new music in creative imagination. Motor imagery, that is, the subjective sensory experience of action in association is also a basic factor, because it is the tap-root of emotional expression and is really an index of musical emotion. For each of these we have serviceable introspection measures.

(d) Memory.-There are many vastly divergent aspects of musical memory in musical talent which may be measured, but if we shall select only one for the present purpose, that one will undoubtedly be memory span; that is, the capacity for grasping and retaining for a moment a group of musical sounds. This measurement is ordinarily made in terms of memory for pitch.

(e) Musical intelligence.-Since the character of the musician is determined largely by the character of his general intelligence, quite apart from music, if we are to limit ourselves to a single test, such a one may be found for children in the so-called "intelligence quotient" which is a rating of intelligence in terms of mental age. For adults corresponding tests are available and may be adapted for musical purposes.

\section{The Rating of Factors not Measured}

The development of experimental technique has led to clearness of analysis and critical procedure in the observation and recording of factors which cannot be put under experimental control. Such observation and rating of factors, with reasonable precision, must furnish very valuable supplementary information for aid in the interpretation of the quantitative measures. The above measurements furnish abundant opportunity for the systematic recording of relevant facts when once knowledge of classification, relationships, and characteristic evidences enter into the critical judgment of the experimenter.

Among the items to be observed in examining the person, record should be kept of voice-quality, register, volume, evidences 
of training-general motor control, as in the shape of the hands, grace and precision of movement, and general alertness. Evidences of rhythmic tendencies, vividness and fertility of imagination, characteristics of memory, musical centers of interests, stock of musical ideas, the expression of musical feeling, temperament and artistic attitudes when off guard, physique, health, and physical development.

Significant biographical data in the form of case history should be gathered bearing upon striking ancestral traits, hereditary diseases, social and vocational status, educational opportunities, impediments which have stood in the way of successful education and achievement, and other significant facts of life history bearing upon the factors at issue. No set form should be followed, but alertness and skill in observing the essentials is desirable.

In these matters of ratings and case history the experimenter should not fill out forms or pad records but should take the same attitude that the physician takes. The physician has in mind the generally recognized varieties of diseases and their symtoms, and in the best practice he makes record of anything which in his judgment may appear to be relevant. The examiner should not pad formal records but should collect relevant facts.

One factor which can not be measured but may possibly be observed systematically for the purpose of tracing transmission through heredity, is that of the musical impulse as shown in a natural craving for music, sustained interest in its pursuit, and a deep feeling of satisfaction in things musical. This impulse, when genuine, rests upon natural bent of mind due mainly to the possession of capacities but also to a general artistic disposition in the form of artistic temperament. The best that we can do, at the present time, is to record all observable evidences of such a driving impulse apart from artificial stimulation and simulation. We shall undoubtedly find interesting relationships between these impulses and the power to achieve both as to amount and kind. It is very desirable to learn to what extent such an instinctive impulse may be lost by very slightly untoward circumstances in early life. It will also be interesting to see to what extent a dominating impulse of this sort is related to lack of capacities or absence of interest in other activities.

\section{Possible Ways of Organizing Investigation}

The laws of the inheritance of musical traits must ultimately be determined by actual experiment on carefully selected matings 
in which the measurements may be repeated for successive generations. Such an undertaking can be fostered only by an agency heavily endowed, of a nation-wide scope, adopting a thoroughly standardized procedure which can be sustained for many years.

In general, it would seem feasible to follow, in an investigation of this sort, the same methods that have been followed so successfully with plants and animals; $i . e .$, to isolate and observe under experimental control, one factor at a time, in all the progeny from a given pair for a certain number of generations. There need be only one restriction in view of the fact that we are dealing with human beings; namely, that we can not breed successive generations for this specific purpose. This, however, is not serious because we can adopt the device of selecting from volunteers in which the factor under control is mated in a known way, and examine them and their children and their children's mates in successive generations. Since this process would be elaborate perhaps several factors might be measured in the same series. The advantage of taking only one factor at a time lies mainly in the fact that this would make it possible to start a pedigree in each case with very conspicuous matings of a capacity. In some cases two or more factors might be found sufficiently conspicuous in the same mating. Full ratings through systematic observations and case histories may be kept quite complete. This is undoubtedly the method of the future. It involves not the slightest infringement upon reasonable sensibilities or proprieties; on the contrary, it should constitute a most fascinating coöperative search for truth.

A more direct procedure would be to aim at the same result by examining large numbers of parents with their children and taking into account the transmission of this factor or factors in one generation. Here we would have the alternative of spending time and effort in selecting conspicuous matings for a given capacity; or by taking families at random and depending upon large numbers of measurements to yield reliable data. The former of these alternatives would undoubtedly be more desirable.

A third method may commend itself best for a pioneer effort in this field; that would be to take a family or families in which conspicuous musical talent has appeared; a family whose children and their mates, and possibly their grandchildren, are reasonably available for visit and examination, and about which there may be records of achievement and descriptions of talent in the ancestry. 


\section{PoINT OF VIEW}

This point of view does not conflict with the artistic and philosophical points of view, both of which regard these same phenomena from entirely different angles. The artist may, in successive attitudes, regard his life from each of these three points of view. As an artist he finds himself in resthetic rapport with Nature without and Nature within-human emotion. As a philosopher he reasons about the relations of this life of music to the life of nature as a part of beauty and truth, and weaves it into his world view. As a scientist he turns upon the same phenomena in a cold microscopic attitude; interested in particulars, causes, conditions, and mental laws.

The point of view here presented is that of the naturalist. Musical life is made up of phenomena in nature all operating according to determinable laws of nature; analyzable, describable, explainable-knowable and worth knowing. 